\title{
La participación del Congreso Nacional en las modificaciones a la Ley de Presupuestos
}

\author{
Sebastián Soto Velasco*
}

\begin{abstract}
RESUMEN
Esta investigación examina las modificaciones que se realizan a las leyes de presupuestos sin aprobación del Congreso Nacional. Como ya es costumbre, numerosas decisiones que se toman en el debate legislativo durante la tramitación de la Ley de Presupuestos son luego modificadas por el Ministerio de Hacienda sin ninguna intervención legislativa. El documento analiza la evolución del debate y la práctica en torno a las modificaciones presupuestarias. Luego teoriza acerca de la importancia de la participación legislativa y estudia modelos comparados que permiten apreciar una mayor participación del Congreso en los debates que implican modificaciones a las decisiones presupuestarias originales. Todo esto permite escrutar críticamente nuestro sistema que debe, por lo mismo, abrirse a eventuales cambios que se esbozan bacia el final de la investigación.
\end{abstract}

Ley de Presupuestos; flexibilidad presupuestaria; Dirección de Presupuestos

\section{Congressional intervention in the modifications of the budget}

\begin{abstract}
This paper examines the modifications to the budget law which are not approbed by the National Congress. As became usual, many congressional decisions during the legislative process of the budget are changed by the Treasury with no congressional intervention. This paper analyses the debate and the practice of budget modifications. Then it goes deeper on normative issues and comparative perspective in order to find other experiences where legislative intervention is reinforced. All this critic scrutiny of the current system give room to changes in the legal framework.
\end{abstract}

Budget; budget flexibility; Budget Office

* Licenciado en Derecho, Pontificia Universidad Católica de Chile. Máster en Derecho (LLM), Universidad de Columbia, Estados Unidos. Doctor en Derecho, Universidad de Chile. Profesor de Derecho Constitucional, Pontificia Universidad Católica de Chile. Correo electrónico: jssoto@uc.cl.

El presente artículo es parte del proyecto Fondecyt No 11170364 .

Agradezco a los ayudantes de investigación María Paz Dulanto, Benjamín Sáez y Sebastián Salazar. Igualmente agradezco a Lucas Sierra e Isabel Giménez por comentarios y críticas a algunas de las ideas expuestas en este artículo que fueron esbozadas antes en mi tesis doctoral.

Artículo recibido el 2.1.2019 y aceptado para su publicación el 4.9.2019. 


\section{INTRODUCCIÓN}

$\mathrm{D}$ urante la discusión de la reforma electoral el 2015 uno de los temas más debatidos fue el costo que generaba el aumento del número de diputados y senadores. Tanto el Congreso Nacional como los representantes del Poder Ejecutivo acordaron que el proyecto no tendría costo fiscal adicional pues el mayor gasto que generarían los nuevos parlamentarios sería absorbido por medio de reasignaciones del presupuesto vigente $^{1}$. Lo mismo fue confirmado durante el debate de la Ley de Presupuestos del 2018 cuando se rechazó la propuesta inicial del Ejecutivo que aumentaba el presupuesto, pues los nuevos gastos se solventarían por la vía de reasignaciones del presupuesto regular ${ }^{2}$.

No obstante lo anterior, en marzo de 2018 la prensa informó un suplemento en la partida presupuestaria correspondiente al Senado de $\$ 2.100$ millones $^{3}$, pues no era posible financiar el aumento del número de parlamentarios sin gasto adicional.

Lo relevante para esta investigación no es la polémica en torno a la proyección de costos de un proyecto de ley o al eventual incumplimiento de un acuerdo político. Esta investigación plantea que las modificaciones a la Ley de Presupuestos sin la aprobación legislativa e incluso, como en este caso, en contra de la voluntad expresada por las cámaras en la Ley de Presupuestos, es cuestionable desde una perspectiva normativa.

Para mostrar lo anterior, esta investigación parte analizando la situación en Chile, tanto en perspectiva histórica (capítulo 2) como en cuanto a su reglamentación y práctica actual (capítulo 3). Luego se examina el asunto normativamente (capítulo 4) y desde dos casos emblemáticos del derecho comparado (capítulo 5). Todo esto permite concluir que las recurrentes modificaciones a las leyes de presupuestos sin intervención legislativa deben ser revisadas (capítulo 6).

\section{Debates y práctica de la Flexibilidad PRESUpuestaria EN NUESTRO DERECHO}

A continuación analizaremos someramente tanto el debate en torno a las modificaciones a las leyes de presupuestos como la práctica de su modificación. Nos centraremos especialmente en el debate que se llevó adelante en los noventa que finalizó con una sentencia del Tribunal Constitucional que zanjó las discusiones constitucionales respecto de la materia.

${ }^{1}$ Informe Financiero. Historia de la Ley 20.840, pp. 14 y 294. Ver también Tribunal Constitucional, 30.3.2015, rol 2777-15, c. 46-54.

${ }^{2}$ Ver Historia de la Ley 21.053, de presupuestos del año 2018, pp. 1074-1078 y 1557.

${ }^{3}$ Decreto 36, Ministerio de Hacienda. 23.01.2018. 


\section{Modificaciones a la Ley de Presupuestos bajo la Constitución de 1833 y 1925}

Las modificaciones a la Ley de Presupuestos han sido habituales en la ejecución presupuestaria en nuestra historia constitucional. El mecanismo para hacerlas ha sido tanto la ley como la potestad reglamentaria aunque, según veremos, es esta última la que ha ganado fuerza en las últimas décadas.

Una primera forma de efectuar las modificaciones a los presupuestos es por la vía de otra norma legal. Al decir de Domingo Amunátegui, fue esta la práctica durante el siglo XIX pues, escribe en 1900, "año a año se presentan en tropel numerosos proyectos de suplementos para los Presupuestos de todos los Ministerios” ${ }^{4}$. Medio siglo después, en 1950, otro Amunátegui, esta vez Gabriel, afirma que “reiteradas prácticas políticas han determinado que esta suplementación constituya un segundo presupuesto periódico" 5 . Y en 1962, Martner ratifica lo señalado cuando anota que las modificaciones a los presupuestos se presentaban en un solo proyecto de ley durante agosto y se aprobaban en los últimos meses del año ${ }^{6}$.

Pero utilizar la ley como mecanismo para modificar los presupuestos no impidió hacer lo mismo por la vía de decretos suplementarios que no requerían aprobación legislativa. Huneeus, en su obra clásica, ya cuestionaba "el abuso de echar mano del sistema irregular e inaceptable de hacer imputaciones a imprevistos, para suplir las faltas de partidas previstas agotadas, en lugar de pedir, como debe hacerse, suplementos al Congreso en cada caso particular" 7 . Y las leyes que regularon el presupuesto fueron paulatinamente ampliando estas opciones. Así la ley de 1884 autorizó a exceder los ítems de la Ley de Presupuestos cuando concurrieran algunas circunstancias tales como gastos generados en leyes posteriores a la promulgación del presupuesto; gastos determinados por sentencias ejecutoriadas; u otros que permitieran solventar las operaciones de empresas públicas ${ }^{8}$. Algunas décadas después, ya en el siglo XX, las normas que regularon los presupuestos fueron aumentando los espacios de flexibilidad permitiendo al Presidente de la República suplementar los gastos en ciertos casos sin una ley especial que lo autorizara9 ${ }^{9}$ En los cincuenta, por ejemplo, se autorizaba al Presidente para ordenar traspasos de fondos entre los capítulos de una misma partida hasta por $5 \%$ de los gastos consultados en el capítulo cuyo total se disminuía. Asimismo, el ministro de Hacienda, por orden del Presidente, podía ordenar traspasos entre los ítems de gastos de un mismo capítulo. Todos estos traspasos se debían informar al Congreso y se podían autorizar el segundo semestre del año presupuestario ${ }^{10}$.

\footnotetext{
${ }^{4}$ Amunátegui, 1900, p. 250.

5 Amunátegui, 1950, p. 511.

${ }^{6}$ Martner, 1962, p. 270.

${ }^{7}$ Huneeus, 1890, p. 225.

${ }^{8}$ Ley de 26.09.1884.

${ }^{9}$ Ley 4.520, 1929.

${ }^{10}$ Decreto con Fuerza de Ley 47, 1959.
} 
Y más evidente aun es la ausencia del Legislativo si se analizan los presupuestos de los servicios públicos descentralizados. Estos, hasta mediados de la década del 70, no integraban la ley de presupuestos que se debatía en el Congreso Nacional sino que eran aprobados por decreto supremo del Presidente de la República. De esta forma, todo el proceso de elaboración y discusión presupuestaria se desarrollaba al interior del Poder Ejecutivo entre la propia institución, el Ministerio de Hacienda y el Presidente de la República quien suscribía el decreto. Lo mismo ocurría con los traspasos durante la vigencia del presupuesto que, según establecía la ley, debían ser aprobados por el jefe de servicio o, en ciertos casos, por el propio Presidente ${ }^{11}$.

Todas estas normas llevan a que un observador externo, Peter Cleaves, afirmará después de estudiar la Administración en Chile en los sesenta que "el Ministerio de Hacienda retiene un considerable margen de maniobra para manipular el presupuesto" durante el año fiscal. Así podía hacer traspasos entre servicios y entre partidas presupuestarias sin autorización legislativa e incluso podía aprovechar los mayores ingresos para suplementar los presupuestos sectoriales ${ }^{12}$.

\section{El debate constitucional en los noventa}

En 1997 el Tribunal Constitucional se pronunció acerca de la constitucionalidad de modificar las leyes de presupuestos por medio de decretos. La sentencia zanjó un debate constitucional que, como veremos, se venía sosteniendo desde el retorno de la democracia.

\section{2.a) Debates constitucionales en el Congreso Nacional y en la academia}

La discusión respecto de flexibilidad presupuestaria en el Tribunal Constitucional fue antecedida por recurrentes debates en el Congreso Nacional al momento de discutir las leyes de presupuestos. Fue común, a inicios de los noventa, que se intentara restringir por la vía de indicaciones las atribuciones que tenía el Ministerio de Hacienda para modificar por medio de decretos los gastos establecidos en la ley de presupuestos ${ }^{13}$. En 1992, por ejemplo, la sala del Senado solicitó un informe a la Comisión de Constitución, la que lo emitió años después, en 1995. En este, la mayoría de sus integrantes determinó que "la existencia de cierto margen de flexibilidad presupuestaria es indispensable para la adecuada y oportuna gestión financiera del Estado, por cuanto al legislador no le corresponde ocuparse en detalle de todos los gastos que es necesario efectuar" ${ }^{14}$. Pero al mismo tiempo, afirmó que esta flexibilidad debe respetar el marco global de gastos autorizados, el destino de los recursos contemplados y las eventuales disminuciones de

\footnotetext{
11 URZÚa y GARCía, 1971, p. 223.

12 Cleaves, 1974 , p. 327.

${ }^{13}$ Historia de la Ley 19.103, de Presupuestos de 1992, en especial pp. 311-341.

${ }^{14}$ Sesión $2^{a}$, en jueves 8 de octubre de 1992, Ordinaria, p. 20.
} 
gastos variables ${ }^{15}$. Aun así sostuvo que la propia Ley de Presupuestos podía autorizar expresamente a exceder el monto global señalado en esta.

Pero el asunto no solo fue objeto de discusión en el Congreso Nacional. También variados académicos se habían pronunciado pertinente a la materia, dando cuenta de una disparidad de criterios que solo vino a zanjar el fallo del Tribunal Constitucional.

En 1992 José Luis Cea escribió que la Ley de Presupuestos es una ley marco y autorizatoria en términos generales o básicos, por lo que las normas de flexibilidad presupuestaria tenían base constitucional ${ }^{16}$. Al año siguiente Jorge Precht sostuvo que el principio de legalidad formal aplicado en materias vinculadas a la hacienda pública debe interpretarse con flexibilidad a la luz del principio del servicio a la comunidad ${ }^{17}$. Y finalmente Alejandro Silva Bascuñán, en un informe elaborado para la Comisión de Constitución con motivo del debate a que se hizo referencia más arriba, sostuvo que las autorizaciones de gasto son meras estimaciones. Por eso la Constitución autoriza a que, por vía administrativa, se modifiquen los gastos totales aprobados por el Congreso Nacional si hay más ingresos que los estimados originalmente ${ }^{18}$.

La posición contraria la sostuvo Enrique Evans ${ }^{19}$ y Jorge Ovalle ${ }^{20}$. Ambos argumentaron por la inconstitucionalidad de las normas de flexibilidad presupuestaria, pues, entre otros argumentos, la tradición chilena había sido siempre que todo gasto debía ser autorizado por ley, por lo que no podía admitirse que la autoridad dispusiera de gastos fiscales sin estar autorizados por ley.

Pero quien más ha profundizado respecto del tema fue Rodrigo Pineda, primero en su tesis de magíster -elaborada antes de la sentencia- y luego en un artículo publicado con posterioridad a la contienda constitucional. En esta última publicación señala que "por razones históricas, doctrinaria y constitucionales resulta fundado afirmar que el Presidente de la República no puede disponer por vía administrativa gastos que excedan los legalmente autorizados ni aun en el caso que los ingresos fueren superiores a los calculados". Asimismo, agrega que ello no impide que el legislador regule expresamente situaciones en que la Administración puede excederse del presupuesto aprobado sin necesidad de ley ${ }^{21}$.

Todo este debate antecedió la contienda constitucional y fue ponderado por el Tribunal Constitucional al momento de resolverla, según expresa la misma sentencia (STC 254, c. 20).

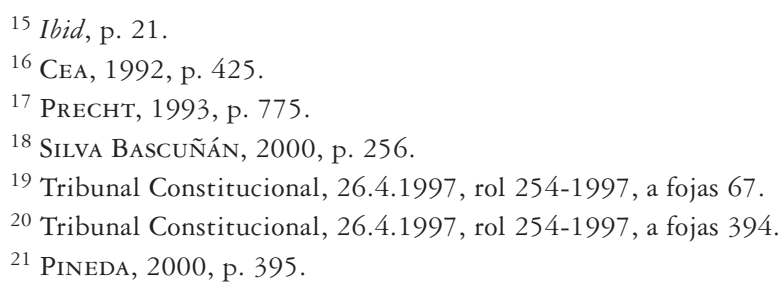




\section{2.b.) La sentencia del TC}

En febrero de 1997 se publicó el decreto supremo que establecía modificaciones presupuestarias para 1997. El decreto regulaba traspasos de recursos entre subtítulos, creación de nuevos subtítulos, modificaciones de ingresos y gastos, creación de programas especiales y otras modificaciones presupuestarias.

Un grupo de senadores presentó un requerimiento al Tribunal Constitucional impugnando el decreto por ser contrario al principio de legalidad del gasto público y a diversas normas constitucionales.

El Tribunal Constitucional resolvió rechazando el requerimiento por la unanimidad de sus integrantes. En lo que interesa, el fallo sostiene que la ley de presupuestos "reúne características que le dan una categoría especial"22. Para justificar la especialidad recurre a diversos argumentos. Dice que se trata de "la herramienta" para satisfacer gran parte de las necesidades públicas; que es imposible una previsión total por parte del legislador (c. 18); que se trata una "ley marco y, por tanto, corresponde al organismo administrativo detallar su ejecución” (c. 22); y que hay razones históricas que permiten sostener que la Ley de Presupuestos se aparta "en varios aspectos de las características y objetivos universalmente reconocidos a la ley". Todo esto sirve de base para justificar una interpretación constitucional "flexible, racional y lógica" del principio de legalidad en materia presupuestaria, donde se admite, en consecuencia, una intensa colaboración de la potestad reglamentaria (c. 24-28).

La sentencia vino a consolidar la práctica hasta la fecha en el que las asignaciones de gasto de la ley de presupuestos podían modificarse por medio de actos administrativos, con las restricciones que estableciera la ley. Así entonces, el asunto dejó de ser constitucional y pasó a ser de potestad exclusiva del legislador, pues en virtud de la ley podía definirse el alcance de la colaboración de la potestad reglamentaria en la modificación de las normas presupuestarias. Y el rol del legislador en esta materia se ha encaminado no a limitar sino que a incorporar cláusulas que obligan a informar el número de los decretos que modifican el presupuesto.

\section{El debate boy}

Actualmente el tema no ha sido objeto de reflexión regular por parte de la academia. Ello parece ser reflejo de una escasa investigación en torno a temas vinculados con los presupuestos del Estado por parte de las ciencias jurídicas ${ }^{23}$. Aun así hay excepciones y algunos autores han expresado críticas a la flexibilidad de las normas que permiten la modificación de los presupuestos por la vía reglamentaria ${ }^{24}$.

22 Tribunal Constitucional, 26.4.1997, rol 254-1997.

${ }^{23}$ Por supuesto en esto hay excepciones. Recientemente Guerrero, 2018, p. 356 y ss. e YrarráZAVAL, 2018 , p. 85 y ss.

${ }^{24}$ Pallavicini, 2015, p. 379 y ss.; Soto, 2017, p. 204 y ss. 
Tampoco ha sido objeto de litigación constitucional. Si bien ha habido sentencias del Tribunal Constitucional sobre materias presupuestarias, ellas no han versado acerca de las normas de flexibilidad sino más bien por las ideas matrices de la Ley de Presupuestos o la iniciativa presidencial ${ }^{25}$. Y, aun cuando de modo indirecto, la preeminencia presidencial en materias presupuestarias que recuerdan una y otra vez las sentencias, podría contribuir a ratificar el criterio del fallo de 1997.

Donde sí el debate parece estar adquiriendo más sustancia es en el Congreso Nacional. En los últimos años han vuelto las discusiones referidas a las normas de flexibilidad en la tramitación de las leyes de presupuestos. Así, para la discusión del presupuesto del 2017 se estableció que la información que debe enviar la DIPRES respecto de los decretos de modificaciones presupuestarias al Congreso Nacional debe incluir un dato adicional. Si antes solo se exigía una especificación de los montos incrementados o disminuidos por subtítulo y partida, a partir de ahora se eleva el estándar de la argumentación. Esto pues también se exige detallar si se trata de "incrementos por aplicación de leyes, reducciones por ajuste fiscal o modificaciones por decisiones de política" ${ }^{26}$. Y en la discusión de la Ley de Presupuestos para el 2019 se discutió una indicación para limitar la facultad de reducir el presupuesto utilizando las normas de flexibilidad presupuestaria respecto de poderes constitucionalmente autónomos, como el Poder Judicial, la Contraloría y el propio Congreso Nacional ${ }^{27}$.

\section{LAS NORMAS DE FLEXIBILIDAD PRESUPUESTARIA Y SU APLICACIÓN}

\section{Las normas}

En teoría, la disposición más relevante que regula la flexibilidad presupuestaria en nuestro derecho es la contenida en el artículo $32 \mathrm{~N}^{\circ} 20$ de la Constitución, esto es, el decreto de emergencia. La norma autoriza que el Presidente, con la firma de todos sus ministros, decrete pagos no autorizados en la ley para atender ciertas necesidades impostergables derivadas de calamidades públicas, conmoción interna y otras circunstancias similares. El total de giros no puede exceder anualmente del $2 \%$ de los gastos autorizados en la Ley de Presupuestos respectiva. Si bien esta atribución presidencial fue invocada regularmente bajo la Constitución del $25^{28}$, hoy su uso es casi inexistente y ha sido reemplazada por las normas legales que regulan la flexibilidad presupuestaria ${ }^{29}$. Otra norma relevante es el artículo 100 que establece, al igual que los textos constitucionales

25 Tribunal Constitucional, 24.12.2007, rol 1005-2007; 30.12.2010, rol 1867-2010; 21.12.2015, rol 2935-2015; 15.12.2017, rol 4118-2017; 22.01.2019, rol 5735-2018.

${ }^{26}$ Ley 20.981, 2016.

27 Ver Historia de la Ley 21.125, de presupuestos para el 2019. En especial pp. 1867 y ss.

28 Silva Cimma, 1992. p. 256 y ss.

29 Desde 1990 a la fecha ha sido utilizado en dos ocasiones con motivo del financiamiento del Transantiago: DS 1178/2008 y DS 1/2009, ambos del Ministerio de Hacienda. 
anteriores, que las tesorerías no podrán efectuar ningún pago sino en virtud de un decreto o resolución expedido por autoridad competente, en el que se exprese la ley o la parte del presupuesto que autorice aquel gasto.

Ambas disposiciones, y en general aquellas que regulan la reserva legal, sirven de base constitucional a lo que el Tribunal Constitucional ha venido a denominar, en la sentencia reseñada más arriba, como la trilogía Constitución, ley y decreto que regula la ejecución presupuestaria y las normas de flexibilidad ${ }^{30}$.

La reglamentación legal de la flexibilidad presupuestaria, por su parte, se encuentra principalmente en el Decreto Ley 1263 de Administración Financiera. Y dentro de este cuerpo legal es el artículo 26 el más relevante. Esta disposición establece como regla general que las regulaciones de los traspasos, incrementos, reducciones y demás modificaciones presupuestarias serán normadas por decreto. Estos decretos se suelen dictar en diciembre, días antes de la entrada en vigencia de la nueva Ley de Presupuestos y son emitidos con la pura firma del ministro de Hacienda ${ }^{31}$.

El mismo artículo determina diversas excepciones dejando reservado a la ley algunos de estos traspasos. Es decir, no es posible por vía de las normas de flexibilidad presupuestaria, sino que se exige una ley para, por ejemplo, la transferencia de fondos entre ministerios; los aportes a las empresas del Estado y a las municipalidades; el incremento de las sumas globales de gasto que la Ley de Presupuestos fija anualmente; entre otras.

El mismo artículo exige la aprobación de una ley para el traspaso a diferentes partidas de la Ley de Presupuestos de "recursos que, previamente, hayan sido traspasados desde ellas al Tesoro Público”. De esta forma, y por oposición, autoriza el traspaso a partidas de la Ley de Presupuestos cuando los montos no provengan de otro ministerio sino que hayan estado en la partida de Tesoro Público. Es esta última la forma habitual que tiene el Ministerio de Hacienda para traspasar fondos con total flexibilidad. Debido a que la partida "Tesoro Público" es aquella que contiene la "caja fiscal” y considerando que el dinero es fungible, los incrementos presupuestarios siempre vienen desde esa partida sin que haya limitación real alguna.

El tema no ha pasado inadvertido en las ocasiones en que se han debatido reformas fiscales. El 2003, en el contexto de una modificación al DL 1263 que profundizó la transparencia y el control presupuestario, se modificó el artículo 26 para limitar este traspaso de recursos, según se puede apreciar del debate en la sala del Senado ${ }^{32}$. Sin embargo, sigue siendo la triangulación de recursos por medio del Tesoro Público la forma habitual de traspasar recursos sin autorización legal. Igualmente, aunque con menos discusión, la Ley de Responsabilidad Fiscal del 2006 permitió usar activos financieros para incrementar el presupuesto; de esta forma, el aumento de los recursos no implicaba, como antes, un aumento de la deuda, sino que un uso de recursos que tenían su

30 Tribunal Constitucional, 26.4.1997, rol 254-1997, c. 19 у 24.

31 Todos ellos pueden encontrarse en el libro Instrucciones para la Ejecución de la Ley de Presupuestos del Sector Público que publica en diciembre de cada año la DIPRES y que se encuentran en la página web de esa institución.

${ }^{32}$ Ver Historia de la Ley 19.896. En especial p. 51 y ss. 
origen en ahorros u otras operaciones financieras que permiten aumentar los recursos sin aprobación del Congreso Nacional.

Junto con las normas legales contenidas ya referidas, cada año las respectivas leyes de presupuestos contienen normas especiales y temporales de flexibilidad presupuestaria. Así, desde 1993 la ley de presupuestos contempla una norma cuasitipo que se repite anualmente en la que especifica excepciones a la reserva legal establecida en el artículo 26 que amplían los espacios para traspasar recursos sin autorización legal previa ${ }^{33}$.

\section{Aplicación. Datos de los últimos presupuestos}

Hay dos formas de constatar la magnitud del alcance de las normas de flexibilidad presupuestaria $^{34}$.

La primera es revisando el presupuesto aprobado en el Congreso Nacional y compararlo con el presupuesto ejecutado por los servicios públicos. Es esto lo que ha hecho Henríquez para los presupuestos entre el 2009 y 2016. Si la comparación se hace a nivel de partidas del Gobierno Central, concluye que en promedio gasta 1,1\% más de lo acordado en las respectivas leyes de presupuestos con un rango que va desde $+9,4 \%$ el 2009 y $-3,8 \%$ el 2013. Agrega el autor que, en los años medidos, los ministerios de Salud, Trabajo, Interior, Hacienda, Defensa y Agricultura presentan "consistentemente -en todos los años- las mayores alzas en su ejecución presupuestaria” 35 .

A nivel de programas presupuestarios la cifra es más intensa: entre 2009 y 2016 la ejecución presupuestaria de los programas fue en promedio $+14,9 \%$, siendo el rango de ajuste más alto $+963 \%$ el 2010 en la Secretaría y Administración General del Ministerio del Interior, posiblemente en razón del terremoto.

El mismo autor da cuenta de varios programas en los que regularmente la ejecución está por encima de lo presupuestado inicialmente (ej. Servicios de salud, Conaf) o que, por el contrario, siempre ejecutan menos de lo aprobado (algunos del Mineduc).

Nada de esto, por cierto, se debe a modificaciones por medio de proyectos de ley sino que al uso de las normas de flexibilidad presupuestaria.

La segunda forma de constatar el alcance de las normas de flexibilidad presupuestaria es examinando los actos administrativos en donde se modifican los guarismos contenidos en las leyes de presupuestos.

${ }^{33}$ De la operación de estas normas ver Pallavicini, 2015, p. 383 y ss.

${ }^{34}$ Otra forma de medir la relevancia de la flexibilidad presupuestaria es revisando la jurisprudencia administrativa pertinente a la materia. La Contraloría hace referencia regularmente en sus dictámenes a las normas de flexibilidad presupuestaria como mecanismo de gestión financiera (Ej. 28961/17; 10135/17; 3139/15; 53915/14; 20241/11). Lo mismo se aprecia en diversos informes de auditoría (Ej. 1173/2015; $64 / 2015 ; 14 / 2012)$

${ }^{35}$ Henríquez, 2017, p. 3. 
La siguiente tabla muestra el número de decretos de modificaciones presupuestarias tramitados entre el 2015 y 2017, lo que da cuenta de una intensa gestión presupuestaria por esta vía ${ }^{36}$.

Número de decretos de modificaciones presupuestarias ingresados a Contraloría

\begin{tabular}{lccr}
\hline & 2015 & 2016 & 2017 \\
\hline Toma Razón & 1688 & 1422 & 1744 \\
\hline Toma Razón Alcance & 2 & 4 & 11 \\
\hline Representación & 1 & 2 & 1 \\
\hline Retirados & 140 & 136 & 134 \\
\hline
\end{tabular}

El cuadro siguiente muestra otra faceta del mismo tema al dar cuenta del número de decretos que, para cada año, hacen alguna modificación a la partida que se señala.

Número de decretos por partida

\begin{tabular}{lcccr}
\hline Partida & 2010 & 2012 & 2014 & 2016 \\
\hline Mineduc & 114 & 86 & 97 & 75 \\
\hline Tesoro Público & 423 & 479 & 545 & 509 \\
\hline Segpres & 19 & 6 & 12 & 13 \\
\hline
\end{tabular}

El cuadro muestra las modificaciones en el presupuesto inicial en un ministerio cuyo presupuesto es de los más cuantiosos (Ministerio de Educación. Mineduc) y en otro ministerio pequeño (Ministerio Secretaría General de la Presidencia. Segpres). También incorpora la partida de Tesoro Público que es la caja del Fisco.

El contenido de los decretos es similar. Contienen incrementos o reducciones de montos en diversos programas; en ocasiones también cambios en las glosas. Así se encuentra un incremento en la asignación de "asesoría y apoyo a la educación escolar" que integra el Programa de Mejoramiento de la Calidad Escolar de la Subsecretaría de Educación. Y así por montones. Los mismos movimientos ocurren en Segpres pero, debido a que es un ministerio que cuenta con menos presupuesto y programas presupuestarios, son menos frecuentes. Y en el caso de Tesoro Público, que contiene los ingresos del Fisco,

${ }^{36}$ Crispi et al. analizan las modificaciones presupuestarias para el período 1995-2002 y concluyen que anualmente se tramitaron en promedio más de 700 modificaciones. CRispi et al., 2004, p. 34. Esta cifra probablemente está subestimada, pues ya el año 1990, según informa la memoria de la Contraloría, los decretos de modificación presupuestaria fueron 1.318. Una cifra similar se presenta en 1991. La información de la tabla fue obtenida de la División de Análisis Contable de la Contraloría General de la República. 
los decretos son tan numerosos que muchos de ellos se refieren a ingresos y gran parte de los gastos se originan en esa partida.

Un dato adicional que da cuenta de la magnitud de los cambios es examinar ya no solo el número de decretos, sino que también la densidad de los mismos. A causa de que usualmente un mismo decreto efectúa modificaciones presupuestarias en diversos servicios y ministerios, analizar el número de páginas del decreto permite ratificar que los cambios son también masivos.

Número de páginas de los decretos ${ }^{37}$

\begin{tabular}{lcccr}
\hline Partida & 2010 & 2012 & 2014 & 2016 \\
\hline Mineduc & 8,2 & 5,3 & 5,2 & 4,6 \\
\hline Tesoro Público & 5,7 & 4,1 & 4,3 & 4,6 \\
\hline Segpres & 23,4 & 24,1 & 13,8 & 10,4 \\
\hline
\end{tabular}

Todas estas cifras muestran una práctica reiterada de modificaciones a la Ley de Presupuestos por la vía de decretos supremos. Tanto las cifras globales como el análisis de algunas partidas dan cuenta de una intensa actividad reglamentaria que modifica las decisiones tomadas en el Congreso Nacional. Si a ello agregamos que en los años analizados hay solo una ley que modificó directamente el presupuesto ${ }^{38}$, no es difícil concluir que los gobiernos tienen amplias atribuciones para modificar los presupuestos una vez aprobados por el Congreso.

\section{Aplicación. El proceso al interior del Poder Ejecutivo y en la Contraloría}

Las modificaciones presupuestarias toman la forma de un decreto supremo firmado por el Ministro de Hacienda por orden del Presidente de la República que está sometido a la toma de razón de la Contraloría General de la República ${ }^{39}$.

Como es común en toda la administración financiera del Estado, en las reasignaciones el Ministerio de Hacienda, y en especial la Dipres, también concentran el poder de decisión. Sea por desconfianza en los ministerios sectoriales ${ }^{40}$ o sea por inercia institucional,

${ }^{37}$ En este gráfico, llama la atención la extensión de los decretos que efectúan traspasos en Segpres en comparación a aquellos que hacen lo mismo en el Mineduc y en el Tesoro Público. La explicación de ello es que el escaso número de decretos lleva a que el promedio aumente considerablemente en caso que haya decretos muy extensos que agrupan variadas modificaciones presupuestarias en todas las partidas. Y es lo que suele ocurrir: el año 2010 hay tres decretos de modificaciones presupuestarias sobre 90 páginas que incluyen a Segpres; y el resto de los años de la muestra es uno cada año, lo que eleva el promedio.

38 Una glosa del presupuesto del 2016 fue modificada por la Ley 21.052 que introduce diversas modificaciones a la normativa educacional.

39 Ver Art. 70 del Decreto Ley 1263, 1975, y Art. 8.1 de la Resolución 1600, 2008.

${ }^{40}$ Vammalle y Ruiz, 2016, p. 41. 
o posiblemente por ambas, el proceso gira en torno a algunos actores de la Dipres: el decreto requiere el visto bueno del Subdirector y del Director de Presupuestos y luego la firma del Ministro de Hacienda.

Antes de eso hay un sinnúmero de interacciones de los servicios y ministerios con el personal de la Dipres; especialmente con el "sectorialista" responsable quien es el funcionario que tiene a su cargo la relación con servicios y ministerios de su sector. Su marco de atribuciones es típicamente parte de las instituciones informales que inundan la cultura institucional de la Dipres. Son personas regularmente de larga trayectoria en el sector público que tienen marcada influencia sobre decisiones de su sector. No por nada un jefe de servicio sostuvo que "al final todo el poder lo tiene el sectorialista de la Dipres" 41 .

La necesidad de la intervención de Dipres en los decretos de modificación presupuestaria hace del proceso "algo pesado", según afirma Hawkesworth $e t$ al. ${ }^{42}$. Y es que es necesario someterse a toda esta tramitación para cualquier cambio incluso, como destaca Von Gersdorff, para algo tan básico como modificar asignaciones presupuestarias en el subtítulo de adquisición de activos no financieros entre los ítems 06 (bardware) y 07 $(\text { software })^{43}$. Visto así, la flexibilidad que muestra el presupuesto en manos del Ejecutivo no se extiende a los servicios y ministerios, sino que es concentrada por la Dipres.

A lo dicho sigue luego la toma de razón en Contraloría que revisa estos decretos en la División de Análisis Contable. Este proceso de control de legalidad no ha permitido levantar un cuerpo de jurisprudencia administrativa que permita conocer los lineamientos del órgano contralor en la materia. De hecho, como muestra la tabla de más arriba, casi no se encuentran representaciones ${ }^{44}$. Y es que todo se inserta en una lógica, común en las relaciones entre la Contraloría y los servicios, de diálogo institucional algo opaco donde los reparos de la Contraloría se ponen en conocimiento de manera informal a la Dipres la que retira el decreto para corregirlo o simplemente desecharlo.

Un dato que sirve para apreciar la carga del trámite es estudiar el tiempo que demora. Si se analizan los decretos de modificación presupuestaria en programas del Mineduc durante el 2016 se aprecia que el tiempo promedio que demoró el decreto en su total tramitación desde su emisión hasta su completa tramitación fue de 22,48 días corridos. El 2014 esa cifra fue de 30,6 días ${ }^{45}$. Si a esto se suma el plazo (indescifrable, ya que se trata de un proceso desformalizado) que demora el proceso al interior del Ministerio de Hacienda, es posible concluir que la tramitación de una modificación

\footnotetext{
${ }^{41}$ Informe de la Comisión de Modernización del Estado, 2017, p. 84.

42 Hawkerworth et al., 2013, p. 35.

43 Von GersdorfF, 2018, p. 544.

${ }^{44}$ La escasa jurisprudencia en torno a este tema en LASTRA, 2014, pp. 85-90.

45 Este cálculo se obtiene de información de los propios decretos que contienen: fecha de emisión del decreto; fecha de recepción en Contraloría; fecha de toma de razón; y fecha de total tramitación según cargo del Ministerio de Hacienda. La diferencia entre ambos años está dada principalmente por la diferencia que existe en cada uno de ellos en la etapa que va desde la emisión a la recepción del decreto en Contraloría. En el 2016 el tiempo entre emisión y recepción es de 2,7 días mientras que en el 2014 es de 13,4.
} 
presupuestaria es un procedimiento que efectivamente puede constituir una carga pesada para los servicios y ministerios.

\section{IV. ¿Por Qué la AUSEncia legislativa ES UN PROBlema? LA MIRADA NORMATIVA}

En Chile, la flexibilidad en la etapa de ejecución del presupuesto ha sido un tema que se ha discutido en el contexto de la gestión pública y no así en lo relacionado con la intervención del Congreso Nacional.

Lo primero no levanta dudas. Es claro que la flexibilidad presupuestaria es vital para una gestión pública capaz de reaccionar a los múltiples desafíos que plantea la sociedad moderna al gobierno. Por eso es que desde hace algunos años se escuchan planteamientos que proponen mayor flexibilidad para administrar el presupuesto por parte de los respectivos jefes de servicio sin que sea necesario solicitar autorización a la Dipres en todos los casos ${ }^{46}$.

El tema es distinto si se enfoca desde el Congreso Nacional. Las normas de flexibilidad presupuestaria que autorizan al Ejecutivo a modificar las leyes de presupuestos han sido objeto de escasa atención. Una vez zanjado por el Tribunal Constitucional la constitucionalidad de las normas de flexibilidad presupuestaria, esta ha sido la práctica habitual al momento de la ejecución de los presupuestos y el Congreso solo se limita a recibir información acerca de los decretos de modificación presupuestaria. Pero, al menos a juicio de un actor político de las últimas décadas como fue Edgardo Boeninger, ello no ha sido inocuo. Hace años escribió que la baja autoevaluación que de sus tareas hace el Parlamento chileno se debía tanto "a la frustración que le ha provocado su rol respecto al Presupuesto" como al hecho que "el Presidente de la República, con posterioridad a la publicación de la Ley, introducía, en ejercicio de su potestad reglamentaria, numerosas modificaciones al presupuesto ya aprobado por el Congreso" 47 .

En abstracto, un sistema presupuestario en el que las modificaciones a la Ley de Presupuestos pudieran hacerse exclusivamente por decisión del Poder Ejecutivo es susceptible de diversas críticas.

Ante todo, no deja de sorprender que una ley pueda ser modificada en aspectos relevantes por una norma de inferior jerarquía, como es un decreto. Y esto no es solo una cuestión que interese a la teoría de las fuentes del derecho, sino que, más relevante para estas páginas, a la teoría democrática sobre la que se construye el pacto social. Y es que las modificaciones a la distribución de gastos también se vinculan con la legitimidad de la decisión política y con otros valores democráticos que tienden a fortalecerse por la deliberación que se lleva a cabo en las legislaturas.

\footnotetext{
${ }^{46}$ Von GersdorfF, 2018; Informe de la Comisión de Modernización del Estado, 2017; Haw KeswORTH et al., 2013, Granados et al., 2009.

${ }^{47}$ Boeninger, 2007, p. 217.
} 
Preguntarse por la legitimidad de la decisión presupuestaria no es una cuestión superficial. Se trata de una decisión redistributiva que toma el dinero recolectado y lo asigna según prioridades definidas por quienes, en nuestro sistema, integran la asamblea deliberativa por excelencia. Por eso es que la intervención de la legislatura en la decisión presupuestaria ha sido un reclamo desde los orígenes del constitucionalismo. Ya lo reclamaba la Carta Magna, la vieja máxima del no taxation without representation y, en nuestro derecho, desde las primeras constituciones ${ }^{48}$. Se trata en definitiva de una forma de validación procedimental que entrega legitimidad a la decisión no solo por su contenido sustantivo sino que también por el mecanismo utilizado para tomar la decisión.

Es cierto que en la distribución de los recursos el debate tiende a ponderar elementos más pragmáticos y adquiere, por ello, menor contenido moral o sustantivo. De ahí la fuerza que han alcanzado estándares de juicio como la eficiencia o la eficacia. Si a eso se suma que los presupuestos han adquirido en las últimas décadas una creciente complejidad, podría argumentarse que el ideal democrático se alcanza con la participación de la legislatura en la decisión inicial y no exige igual intervención en modificaciones parciales asociadas a coyunturas imposibles de prever.

Pero ello no quita la necesidad de fortalecer la legitimidad de al menos algunas de las decisiones redistributivas. Si la decisión principal fue objeto de deliberación, las decisiones que se aparten del resultado del proceso legislativo también debieran ser objeto de alguna deliberación. Además, tampoco están exentas de una exigencia de legitimidad. Todo ello, especialmente si superan un cierto umbral que las aleja excesivamente de aquello que se discutió en la ley de presupuestos o que, aun sin haber sido discutido, se presume como una decisión relevante para la comunidad política.

$Y$ es que una reducida participación del Congreso incluso en instancias posteriores a la aprobación del presupuesto amenaza con dañar valores democráticos esenciales que la deliberación que se lleva a cabo en las legislaturas tiende a fortalecer. Así, entre otros, la transparencia del proceso legislativo suele ser mayor a aquella que presenta los procesos al interior de la administración. Lo mismo puede decirse de la participación y el control. La participación en las asambleas no siempre es óptima, pero, al menos en nuestro sistema, está muy por sobre la que se da en el procedimiento administrativo. Y lo mismo puede decirse del control donde la legislatura es un espacio para el control político que, de lo contrario, es inexistente en las modificaciones a la Ley de Presupuestos.

Más complejo se torna el asunto si se analiza desde la igualdad política y el principio de mayoría que atraviesa el ideal democrático. Como se vio al iniciar esta publicación, un asunto definido por la mayoría podría ser enmendado por el Ministro de Hacienda por medio de un decreto. Es decir, los mismos argumentos que persuadieron a la mayoría legislativa en el Congreso para determinar un nivel de gasto podrían servir a la autoridad financiera para tomar una decisión diversa.

E igualmente complejo es el asunto si se mira desde los pesos y contrapesos necesarios para el ejercicio de un poder limitado. Es cierto que la autoridad financiera que

\footnotetext{
${ }^{48}$ Bronfman et al., 2013, p. 371.
} 
concentra toda la potestad para modificar las asignaciones de gasto puede pretender reclamar para sí un uso más eficiente de los recursos que aquel que darían parlamentarios más interesados en satisfacer las necesidades de sus electores. Esta crítica, recurrente en el debate presupuestario, ha llevado a reducir las potestades legislativas en las decisiones de gasto pero nunca ha pretendido excluir totalmente la participación de la legislatura de tales decisiones. Ello porque pretenderlo así -sea en el debate presupuestario inicial o en sus modificaciones- constituye una severa vulneración a los pesos y contrapesos sobre los que se debe construir el arreglo institucional. De lo contrario, la pretendida eficiencia degenerará en arbitrariedad por la falta de controles; o al menos verá dañada su legitimidad pues será percibida como una decisión de uno en perjuicio de otros muchos.

¿Quiere esto decir que el ideal democrático o los pesos y contrapesos exigen la aprobación de una ley ante cualquier modificación de los presupuestos? Posiblemente no. Lo exigible es un procedimiento que permita una participación legislativa que favorezca la deliberación, la transparencia y el control. Esto sin dañar la flexibilidad que exige gestionar un presupuesto en el Estado moderno. Algo de eso se encuentra en el derecho comparado, como pasaremos a ver a continuación.

\section{Modelos COMPARAdos ${ }^{49}$}

Wehner, en una aproximación global, sostiene que, salvo para el caso de Estados Unidos que analizaremos a continuación, en la gran mayoría de los países las modificaciones por parte del Ejecutivo a las asignaciones presupuestarias están fuera del efectivo control parlamentario ${ }^{50}$. Y agrega, específicamente respecto de los aumentos de presupuesto, que si bien están limitados, son fuente de cierta discreción por parte de la Administración que termina permitiendo aumentos unilaterales de las cifras aprobadas 51 .

En Latinoamérica el fenómeno se presenta con especial intensidad debido a las amplias delegaciones legislativas que hace el Congreso en materia presupuestaria y al extenso uso de decretos presidenciales para modificar el presupuesto ${ }^{52}$. Si bien la participación de las legislaturas varía según el país y la operación específica de que se trate, un estudio realiza un panorama general que muestra un conjunto de operaciones que no requieren la intervención del Congreso en la mayoría de los países de la región (recortes presupuestarios, adecuación de los presupuestos a cambios en la economía, creación de nuevos programas, transferencias dentro de las mismas cifras globales, entre otros $)^{53}$.

El estudio de marcos regulatorios comparados permite mostrar cómo otros arreglos institucionales exigen la participación legislativa en ciertos casos, mientras que en otros esta puede obviarse si existen diversos controles y mecanismos que regulen adecuadamente

\footnotetext{
${ }^{49}$ Las ideas que siguen están tomadas de mi tesis doctoral Soто (2016), pp. 295-304.

50 WeHNER, 2010, p. 32.

51 WeHNER, 2010, p. 37.

52 SANTISO, 2005, p. 19.

53 Curristine y Bas, 2007, pp. 11-20. Para un análisis aplicado ver Hallerberg, Mark et al., 2009.
} 
la decisión presupuestaria. En particular, Estados Unidos y Francia presentan modelos que conviene analizar: el primero porque, como se verá, tiene un Congreso con intensa intervención en las modificaciones presupuestarias que de todas formas deja espacios a la flexibilidad; el segundo porque, antes de la reforma que se narrará, presentaba un cierto parecido con la situación nacional actual.

\section{El caso de Estados Unidos}

El Congreso de Estados Unidos concentra un importante cúmulo de atribuciones en materias presupuestarias que no terminan una vez despachada la Ley de Presupuestos.

Lo primero que debe señalarse es que la ejecución presupuestaria en Estados Unidos es bastante descentralizada, dentro de un marco de guías y regulaciones generales. De esta forma, el Congreso asigna fondos directamente a las agencias, las que manejan sus propias finanzas. El rol de la Oficina de Presupuestos es, por tanto, limitado y selectivo ${ }^{54}$. En el uso de esta autonomía podemos distinguir tres posibles operaciones que se inscriben dentro del marco de flexibilidad presupuestaria que gozan las agencias: las postergaciones, las cancelaciones y las transferencias.

Las dos primeras requieren de aprobación legislativa ${ }^{55}$ y la intervención del Contralor General quien debe emitir un informe contrastando la información e impactos que cuantificó el Ejecutivo respecto de la postergación o cancelación ${ }^{56}$.

En lo que respecta a las transferencias de recursos la regla general es que, como en los anteriores, estas solo se pueden realizar si existe autorización legal para ello. En algunos casos, el Congreso concede en las leyes de presupuesto autorizaciones generales a ciertos ministerios para efectuar movimientos de recursos entre programas o líneas presupuestarias sin autorización. Pero ello es relativamente excepcional.

Aun así, hay otra especie de transferencia -las llamadas reprogramaciones- donde las reglas son más dispersas. Estas son modificaciones que hace una agencia dentro del mismo programa o línea presupuestaria para gastarlas con un propósito distinto al contemplado por el Congreso al aprobar la ley. La regla general es que las agencias son autónomas para hacer reprogramaciones salvo que haya una prohibición en contrario. Incluso la Corte Suprema se pronunció señalando que no era necesario una autorización legal expresa para reprogramar ${ }^{57}$.

Sin embargo, una costumbre extendida desde hace años es que la agencia respectiva informa antes o después a la comisión de ambas ramas con la que guarda más relación. En algunos casos excepcionales, la autorización previa de la comisión está contemplada en la ley. Pero la mayoría de las veces se origina en acuerdos informales o instrucciones sin fuerza legal que emanan de la propia comisión ${ }^{58}$.

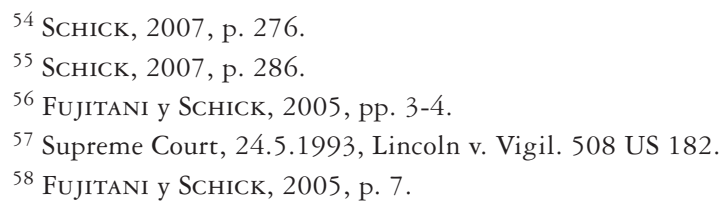


Por último, es importante señalar que dentro del Ejecutivo la reprogramación queda en gran medida en manos de la agencia respectiva y su relación con la comisión legislativa. En otras palabras, la Oficina de Presupuesto del Poder Ejecutivo no tiene herramienta alguna para evitar la reprogramación e incluso carece de instrumentos eficaces para informarse previamente.

\section{El caso de Francia}

En la última década Francia ha hecho profundos cambios a su proceso presupuestario que incluyeron las reglas que rigen la ejecución del gasto. En relación a esta el modelo es distinto al de Estados Unidos pues entrega una alta cuota de flexibilidad para que la burocracia ejecute el presupuesto en el marco general que establece año a año la Ley de Presupuestos. Junto con eso, se modificó la forma de estructurar el presupuesto y se aumentaron las formas de control ex post. Asimismo, aun en este marco de flexibilidad, el Parlamento mantiene cuotas de control pues no delegó completamente la potestad en el Poder Ejecutivo.

Hasta antes de la nueva ley de Administración Financiera francesa, dictada el 2001 y que entró a regir plenamente el 2007, la ejecución presupuestaria estaba sometida a complejas reglas y operaciones respecto de las cuales el Parlamento no tenía conocimiento 59 .

Con la ley de 2001, como coinciden diversos autores, se entrega un alto grado de flexibilidad a la burocracia en el empleo de los recursos presupuestarios al punto que "en el interior de un programa, el gestor dispone de una libertad casi total para redistribuir" los recursos asignados ${ }^{60}$. Esta libertad que la ley francesa le entrega a cada oficina pública para usar libremente las asignaciones presupuestarias y así maximizar el resultado en la implementación del programa, se conoce como fungibilidad. Y ella ha sido elevada a la categoría de principio en el derecho presupuestario francés ${ }^{61}$. En cambio este tiene una limitación que dice relación con el gasto en personal, los que no pueden ser excedidos por la vía de transferencias al interior del programa. La razón de esta diferenciación es el compromiso de largo plazo en las finanzas públicas que importa la decisión de contratación de personal ${ }^{62}$.

Para la gran mayoría de las asignaciones presupuestarias los montos globales constituyen techos que no pueden sobrepasarse. Respecto de las rebajas, el Ejecutivo está autorizado a disminuir una asignación por decreto pero cumpliendo los siguientes requisitos: i) Informe previo del Ministerio de Finanzas; ii) No puede superar el 1,5\%

\footnotetext{
59 OCDE, 2004, p. 213.

${ }^{60}$ Giménez, 2008, p. 43.

${ }^{61}$ Kirat, 2010, p. 6.

${ }^{62}$ Maherzi, 2005, p. 787. Esta norma se complementa con los techos en el número de personal que fija anualmente la ley de presupuestos.
} 
del total del programa; iii) Informar previamente a la comisión legislativa relevante ${ }^{63}$. Si la rebaja supera el porcentaje señalado, se requiere aprobación legislativa.

\section{Conclusión}

Como se puede apreciar, de los modelos comparados que se han examinado puede concluirse, ante todo, que los servicios gozan de cierta flexibilidad interna para el manejo de sus presupuestos sin que deban solicitar autorizaciones a las oficinas presupuestarias respectivas. En Estados Unidos esa tendencia al manejo flexible del presupuesto es antigua, mientras que en el caso francés es producto de una modificación que ya tiene una década de aplicación.

El segundo punto relevante es que la participación legislativa es requerida en ciertas circunstancias. Así, el presupuesto no se ejecuta de espaldas a la legislatura sino que, para ciertas modificaciones, se requiere su intervención. En el caso de Estados Unidos la vinculación con el Congreso es mucho más intensa que en el sistema francés. Pero lo relevante es que en ambas experiencias hay operaciones que solo pueden efectuarse previa autorización legal.

\section{Proyecciones para ChILE}

Se ha visto en estas páginas que las modificaciones a la Ley de Presupuestos son regularmente definidas sin intervención legislativa. También se ha teorizado respecto de la importancia de la participación del Congreso Nacional en la definición de algunas de estas modificaciones. Surge entonces la pregunta evidente: ¿cuál es el nivel de flexibilidad razonable? ¿Cuándo debe o no intervenir la legislatura?

Si se analiza en abstracto, una regla excesivamente favorable al Ejecutivo en las modificaciones presupuestarias de la Ley de Presupuestos ya aprobada torna ineficaz todo debate en su fase legislativa. Si eso ocurre, como dice Alesina et al., "todo el proceso presupuestario resulta menos significativo" 64 . Ello por cuanto el Congreso podría tener capacidad para influir e incluso tomar la decisión respecto de la asignación de los recursos. Pero de nada serviría eso si luego, por la vía administrativa y sin intervención alguna del Congreso, el Poder Ejecutivo tiene autorización para modificar esa decisión. Incluso más, aun cuando el objetivo sea reducir el déficit fiscal y autorizar al Ejecutivo solo a reducir recursos, es posible -como hace Alesina et al.- levantar algunas dudas. En efecto, señalan, el Ejecutivo puede tener incentivos a enviar presupuestos sobrevalorados o a dejar de ocupar el presupuesto como una herramienta para asignar prioridades de política pública. Ello quitaría importancia y transparencia al proceso presupuestario.

\footnotetext{
63 OCDE, 2004, p. 204.

${ }^{64}$ Alesina et al., 1999, p. 259.
} 
Pero la contrapartida tampoco se aprecia como favorable. Exigir intervención legislativa en toda modificación presupuestaria terminaría congelando un presupuesto que, por definición, se construye sobre supuestos. Sería así una excesiva rigidización que agregaría lentitud al funcionamiento de la burocracia y a la toma de decisiones. Ello se enfrenta con la tendencia de las últimas décadas de dar mayores espacios de flexibilidad a los órganos públicos para ejecutar el presupuesto exigiendo como contrapartida resultados ${ }^{65}$.

En cualquier caso, las reglas acerca de flexibilidad deben combinar adecuadamente tanto el control inherente a la existencia de una ley de presupuestos -esto es, que los guarismos discutidos en las legislaturas no sean cifras meramente referenciales- como la eficiencia necesaria para ejecutar el gasto público en un contexto dinámico. En este contexto entonces, se requiere combinar ciertos espacios de rigidez del contenido de la Ley de Presupuestos con otros espacios de flexibilidad dentro del marco presupuestario, preferentemente resorte del servicio que ejecuta el programa.

Sobre esta base se puede avanzar en dos niveles.

El primero es entre las diversas asignaciones presupuestarias - personal, gasto corriente, inversión, etc.- de un mismo programa o servicio. En tal caso los guarismos incorporados deben, al igual que en el caso francés, constituir cifras que admitan reasignaciones dentro del mismo programa o servicio, con el fin de no limitar el dinamismo propio de la Ejecución del gasto. Algunas de estas modificaciones debieran requerir el visto bueno de la autoridad presupuestaria, de forma de consagrar un control interno.

Aun así, la regla debiera tener algunas limitaciones. Una de ellas es restringir el incremento de algunas asignaciones que puedan constituir gasto permanente; como es el caso del gasto en personal en el modelo francés. También es razonable que algunos de estos ítems individualmente considerados no admitan modificación sin la aprobación legislativa. Ello es especialmente relevante si el guarismo fue objeto de debate y aprobación legislativa individual. La forma de concretar esta regla es que la propia Ley de Presupuestos sería la que establezca que ciertos guarismos constituyan límites insuperables. Es este el camino más explícito para lograrlo. También puede consagrarse una regla más general que prohíba aplicar ciertas reglas de flexibilidad presupuestaria - por ejemplo el incremento de recursos- en caso de existir una voluntad expresa de alguna de las cámaras manifestada en una votación que aprueba una reducción.

Un segundo nivel son las modificaciones presupuestarias en las cifras globales de programas y servicios públicos, es decir, cuando ya no se trata de una reasignación interna sino que se aumenta el presupuesto global del ministerio o servicio. Ello puede tener su origen en cambios en las proyecciones iniciales de ingresos o en el surgimiento de nuevas prioridades que aconsejan reasignar recursos existentes. Debido a que el Congreso Nacional tuvo a la vista ese marco global al momento de tomar las decisiones políticas propias del debate presupuestario, y no se trata entonces de la gestión específica de los recursos asignados a un programa, debiera volver a participar quien fue un actor inicial en la definición de la política de gasto fiscal.

\footnotetext{
${ }^{65}$ Posner y PArk, 2007, pp. 15-17.
} 
La forma de participación legislativa puede ser diversa. Una primera, es que se siga el procedimiento legislativo regular; pero ello amenaza con entrabar excesivamente la gestión financiera fiscal que necesita de dinamismo. Una segunda es que la intervención se concentre en la Comisión Mixta de Presupuestos. Esta fórmula, reforma constitucional mediante, es la que a mi juicio presenta las mayores ventajas. Ante todo deja en manos de la comisión especializada la ratificación de la decisión, lo que garantiza un marco conocido y posiblemente predecible de debate. Asimismo, la atribución empodera a la Comisión de Presupuestos y, por ello, la transforma en una contraparte más calificada del poder presidencial.

A lo anterior debe agregarse un proceso expedito que permita aprobar las modificaciones presupuestarias señaladas. Este debe tener un plazo relativamente breve para la votación, después de esto debiera operar una regla de silencio positivo, es decir, en caso de no votarse en la Comisión la modificación se entiende aprobada. De esta forma, se evitan tácticas dilatorias. Asimismo, la regla general debiera ser que la autorización se requiere antes de la tramitación del respectivo acto administrativo que modifica el presupuesto, salvo casos excepcionales y urgentes donde la ratificación se puede obtener ex post. Por último, también se debiera establecer un mecanismo para que, cuando así lo acuerde la Comisión de Presupuestos si concurren ciertas causales preestablecidas, sea la sala de ambas Cámaras las que deban ratificar la decisión dentro de los plazos fijados. Ello, por ejemplo, si se está desfinanciando la totalidad de un programa aprobado o se está modificando la cifra autorizada en un porcentaje muy elevado.

\section{Conclusiones}

En estas páginas se ha mostrado que las modificaciones a la Ley de Presupuestos sin intervención legislativa ha sido algo regular en nuestra historia constitucional. Bajo el imperio de la Constitución de 1833 y de 1925 el asunto fue objeto de críticas sin que por ello se acotaran las normas que regulaban la flexibilidad presupuestaria. A partir de 1990 y, en especial tras el fallo del Tribunal Constitucional de 1997, se consolidó una práctica que no ha recibido especial atención de la doctrina y cuya masividad ha sido develada en estas páginas.

Que el Ejecutivo pueda modificar las leyes de presupuestos sin intervención legislativa es cuestionable normativamente. Esto en especial si se analiza desde la legitimidad de la decisión o desde otros valores democráticos tales como la deliberación, el principio de mayoría o los pesos y contrapesos. Igualmente puede cuestionarse si se examina desde arreglos constitucionales comparados que, aun con flexibilidad en la gestión, exigen cierta participación legislativa en decisiones relevantes.

Todo esto sirve de base a un escrutinio crítico de nuestro sistema de modificaciones presupuestarias que, como se expone en el capítulo final, abre proyecciones de cambio en la regulación vigente. 


\section{BIBLIOGRAFÍA}

Alesina, Alberto; Hausmann, Ricardo; Hommes, Rudolf; Stein, Ernesto, 1999: "Budget institutions and fiscal performance in Latin America", Journal of Development Economics, volumen $59 \mathrm{~N}^{\circ} 2$.

Amunátegui, Gabriel, 1950: Manual de Derecho Constitucional, Santiago, Editorial Jurídica de Chile. Amunátegui, J. Domingo, 1900: Resumen de Derecho Administrativo aplicado a la Legislación de Chile, Montevideo, Imprenta La Razón. Tribunal Constitucional de Chile. Colección Obras de Derecho Público.

Boeninger, Edgardo, 2007: Políticas Públicas en Democracia. Institucionalidad y Experiencia Chilena. 1990-2006, Santiago: Uqbar Editores.

Bronfman, Alan; Cordero, Eduardo; Aldunate, Eduardo, 2013: Derecho Parlamentario Chileno: funciones y atribuciones del Congreso Nacional. Santiago: Legal Publishing.

CEA, José Luis, 1992: "Sobre el Principio de Legalidad Presupuestaria”, Revista Chilena de Derecho, volumen $19, \mathrm{~N}^{\circ} 3$.

Informe de la Comisión de Modernización del Estado, 2017: Un Estado para la Ciudadanía. Santiago, Centro de Estudios Públicos. Disponible en https://www.cepchile.cl/cep/site/ artic/20171109/asocfile/20171109124242/un_estado_para_la_ciudadania_cep_pdf. [Fecha de consulta: 2.1.2019].

Cleaves, Peter, 1974: Bureaucratic Politics and Administration in Chile, Berkeley: University of California Press.

Crispi, J., Vega, A., Cooper, A., Roeschmann, J.A., 2004: Reasignaciones presupuestarias en Chile: conceptualización y análisis cuantitativo, Santiago, Estudio de Finanzas Públicas. Disponible en http://www.dipres.gob.cl/598/articles-21659_doc_pdf.pdf. [Fecha de consulta: 2.1.2019].

Curristine, Teresa y BAs, María, 2007: "Budgeting in Latin America: Results of the 2006 OECD Survey”, OECD Journal on Budgeting, volume 7, $\mathrm{N}^{\circ} 1$. Disponible en http://www.oecd.org/ gov/budgeting/oecdjournalonbudgeting.htm. [Fecha de consulta: 2.1.2019].

Fujitani, Takeshi y SHIRCK, Jared, 2005: "Executive Spending Powers: The Capacity to Reprogram, Rescind and Impound”, Briefing Paper $N^{\circ}$ 8. Federal Budget Policy Seminar. Harvard Law School. Disponible en http://www.law.harvard.edu/faculty/hjackson/ExecutiveSpendingPowers_8. pdf. [Fecha de consulta: 2.1.2019].

Giménez, Isabel, 2008: Las Competencias Presupuestarias del Parlamento, Madrid: Centro de Estudios Políticos y Constitucionales.

Guerrero, José Luis, 2018: La Constitución Económica Chilena, Santiago: Ediciones DER.

Hallerberg, Mark; Scartascini, Carlos; Stein, Ernesto, 2009: Who decides the Budget? A political economy analysis of the Budget process in Latin America, Cambridge: Harvard University Press.

Hawkerworth, I., Huerta, O. y Robinson, M., 2013: "Selected budgeting issues in Chile: Performance budgeting, médium-term budgeting, budget flexibility", OECD Journal on Budgeting, volumen 12, $\mathrm{N}^{\circ} 3$. Disponible en http://www.oecd.org/gov/budgeting/oecdjournalonbudgeting.htm. [Fecha de consulta: 2.1.2019].

Henríquez, Manuel, 2017: ¿Qué tan distinto gastan las instituciones públicas en relación a sus presupuestos aprobados por ley? Análisis de los ajustes que se realizan a los presupuestos iniciales de los servicios públicos. Informe Observatorio del Gasto Fiscal en Chile. Disponible en https:// observatoriofiscal.cl/ARCHIVOS/Biblioteca/Informe_Ajustes_Presupuestarios.pdf [Fecha de consulta: 2.1.2019].

Huneeus, Jorge, 1890: La Constitución ante el Congreso. Tomo I, Santiago, Imprenta Cervantes. 
KIRAT, Thierry, 2010: "Performance-based budgeting and management of judicial courts in France: an assessment", International Journal for Court Administration, volumen 2, No 2.

Lastra, Carolina, 2014: Tratado Jurisprudencial de Derecho Administrativo. Ley Orgánica de Administración Financiera del Estado Interpretada. Tomo VIII. Santiago: Thomson Reuters.

Maherzi, Djalel, 2005: Budget Reform in France: Towards a New Managerial Approach, en Stanislav Poloucek y Daniel Stavarek, Future of Banking after the year 2000 in the world and in the Czech Republic. Karviná: Silesian University.

OCDE, 2004: “The Legal Framework for Budget Systems. An International Comparison”, OCDE Journal on Budgeting, volumen 4, No 3. Disponible en http://www.oecd.org/gov/budgeting/ oecdjournalonbudgeting.htm. [Fecha de consulta: 2.1.2019].

Pallavicini, Julio, 2015: Derecho Público Financiero. Santiago, Thomson Reuters.

Pineda, Rodrigo, 2000: "Las potestades constitucionales del gobierno y el Congreso Nacional en materia de gasto público", Revista Chilena de Derecho, volumen 27 N 2.

Posner, Paul y Park, Chung-Keun, 2007: "Role of the Legislature in the Budget Process: Recent Trends and Innovations", OECD Journal on Budgeting, volumen 7, $\mathrm{N}^{\circ} 3$. Disponible en http:// www.oecd.org/gov/budgeting/oecdjournalonbudgeting.htm. [Fecha de consulta: 2.1.2019].

Precht, Jorge, 1993: "Principios Jurídicos de la Hacienda Pública", Revista Chilena de Derecho, volumen $20, \mathrm{~N}^{\circ} 2 / 3$.

Santiso, Carlos, 2005: Budget Institutions and Fiscal Responsability. Parliaments and the Political Economy of the Budget Process in Latin America, Washington DC: World Bank Institute.

Schick, Allen, 2007: The Federal Budget. Politics, Policy, Process, 3a Edición, Washington DC: Brookings Institution Press.

Silva Bascuñán, Alejandro, 2000: Tratado de Derecho Constitucional. Tomo V, Santiago: Editorial Jurídica de Chile.

Silva Cimma, Enrique, 1992: Tratado de Derecho Administrativo Chileno y Comparado. Vol. 1, Santiago: Editorial Jurídica de Chile.

Sото, Sebastián, 2016: Pesos y contrapesos en la distribución de competencias presupuestarias entre el Presidente de la República y el Congreso Nacional. Tesis para optar al grado de Doctor en Derecho de la Universidad de Chile. Santiago.

Urzúa, Germán y García, Ana María, 1971: Diagnóstico de la Burocracia Chilena (1818-1969), Santiago: Editorial Jurídica de Chile.

Vammalle, Camila y Ruiz Rivadeneira, Ana María, 2016: "Budgeting in Chile”, OECD Journal on Budgeting, volume 16, No 3. Disponible en http://www.oecd.org/gov/budgeting/ oecdjournalonbudgeting.htm. [Fecha de consulta: 2.1.2019].

Von GersdorfF, Hermann, 2018: "El proceso presupuestario en Chile: opciones de reforma”, en Isabel Aninat y Slaven Razmilic (editores), Un Estado para la Ciudadanía, Santiago, Centro de Estudios Públicos, pp. 533-574.

Wehner, Joachim, 2010: Legislatures and the Budget Process. The Myth of Fiscal Control, United Kingdom: Palgrave Mac Millan.

Yrarrázaval, Arturo, 2018: Manual de Derecho Económico, Santiago: Ediciones UC.

Normas jurídicas citadas:

LEY QUE FIJÓ LA FORMA EN QUE DEBEN RECAUDARSE LAS CONTRIBUCIONES FISCALES Y MUNICIPALES, Y EN LA QUE DEBEN PRESENTARSE los PRESUPUESTOS DE GASTOS DE LA REPÚBLICA, publicada el 26 de septiembre de 1884.

LEY 4.520, publicada con fecha 9 de enero de 1929. 
Ley 20.981. Ley de Presupuestos para el Sector Público correspondiente al año 2017, publicada el 15 de diciembre de 2016.

Decreto con Fuerza de Ley 47. Modifica la Ley Orgánica de Presupuestos, publicado con fecha 4 de diciembre de 1959.

Decreto Ley 1.263. Decreto Ley Orgánico de Administración Financiera del Estado, publicado con fecha 28 de noviembre de 1975 .

Resolución 1.600. Fija Normas sobre Exención del Trámite de Toma de Razón, publicada con fecha 6 de noviembre de 2008 .

Jurisprudencia citada:

Corte Suprema de Estados Unidos, sentencia de fecha 24 de mayo de 1993, Lincoln v. Vigil. 508 US 182 (1993).

Tribunal Constitucional, sentencia de fecha 26 de abril de 1997, rol 254-1997.

Tribunal Constitucional, sentencia de fecha 24 de diciembre de 2007, rol 1005-2007.

Tribunal Constitucional, sentencia de fecha 30 de diciembre de 2010, rol 1867-2010.

Tribunal Constitucional, sentencia de fecha 30 de marzo de 2015, rol 2777-2015.

Tribunal Constitucional, sentencia de fecha 21 de diciembre de 2015, rol 2935-2015.

Tribunal Constitucional, sentencia de fecha 15 de diciembre de 2017, rol 4118-2017.

Tribunal Constitucional, sentencia de fecha 22 de enero de 2019, rol 5735-2018. 
